\title{
Experimental Study of Chemical Composition of Hangzhou Soft Clay
}

\author{
Jieqing Huang*, Xingwang Liu and Guoqiang Cao \\ Zhejiang Province Institute of Architectural Design and Research, Hangzhou 310006, China \\ *Corresponding author
}

\begin{abstract}
X-ray energy dispersive spectrometer (EDS) and X-ray diffraction (XRD) tests are performed to investigate the chemical composition of Hangzhou soft clay. For comparison purposes, the above two tests are carried out on Hangzhou stiff clay. Based on EDS results, sulfur(S) can't be found in Hangzhou stiff clay but it can be found in Hangzhou soft clay. The existence of humus is confirmed because $S$ is one of main elements of humus. It can be seen from XRD results that the Quartz content and Anorthite content in Hangzhou soft clay are less than that in Hangzhou stiff clay. However, the Chlorite content and Phlogopite content in Hangzhou soft clay are more than that in Hangzhou stiff clay. According to Mohs' scale of hardness, it can be roughly judged that the compressibility of Hangzhou soft clay is higher than that of Hangzhou stiff clay.
\end{abstract}

Keywords-X-ray energy dispersive spectrometer; X-ray diffraction; Hangzhou soft clay

\section{INTRODUCTION}

Hangzhou soft clay is widely deposited on the Hangjiahu plain in Zhejiang Province. Its high compressibility can cause the excessive settlement. Some scholars did research on the macro behavior of Hangzhou soft clay [1 3]. 1D oedometer tests were performed on Hangzhou soft clay and Hangzhou stiff clay. It was observed that the final settlement of Hangzhou soft clay is much larger than that of Hangzhou stiff clay under the same load. Moreover, the secondary consolidation behavior of Hangzhou soft clay is remarkable. It was worth noting that two Hangzhou soft clay samples exhibit tertiary consolidation behavior [4]. Ichikawa et al. [5] found that bentonite also shows the tertiary consolidation behavior. After these two specimens were opened, some dark-gray-colored stains were observed on the surfaces and they had an intense rotten smell. Based on the above phenomena, it was conjectured that humus exists in Hangzhou soft clay and it causes the tertiary consolidation behavior.

However, further chemical analysis was not performed on Hangzhou soft clay to explain the high compressibility and verify the existence of humus. In this paper, X-ray energy dispersive spectrometer (EDS) and X-ray diffraction (XRD) tests are carried out on natural Hangzhou soft clay samples. Then the chemical composition of Hangzhou soft clay is analyzed. The above two tests are performed on natural Hangzhou stiff clay samples for comparison purposes.

\section{EXPERIMENTAL DETAILS}

\section{A. Sample Preparations}

Undisturbed Hangzhou soft clay samples and Hangzhou stiff clay samples were achieved in Zijingang Campus of Zhejiang University. The basic properties of two kinds of samples are summarized in Table I[4].

TABLE I. BASIC PROPERTIES OF HANGZHOU SOFT CLAY AND HANGZHOU STIFF CLAY

\begin{tabular}{|c|c|c|}
\hline Properties & Hangzhou soft clay & $\begin{array}{c}\text { Hangzhou stiff } \\
\text { clay }\end{array}$ \\
\hline Specific gravity $G_{\mathrm{s}}$ & 2.67 & 2.65 \\
\hline $\begin{array}{c}\text { Saturated unit weight } \\
\gamma_{\text {sat }}\left(\mathrm{kN} / \mathrm{m}^{3}\right)\end{array}$ & 17.74 & 19.30 \\
\hline Natural water content $w(\%)$ & 44.86 & 13.05 \\
\hline Natural void ratio $e$ & 1.18 & 0.55 \\
\hline Plastic limit $w_{\mathrm{P}}(\%)$ & 20.0 & 18.6 \\
\hline Liquid limit $w_{\mathrm{L}}(\%)$ & 41.2 & 34.2 \\
\hline
\end{tabular}

The undisturbed samples are trimmed into small cubes carefully. These cubes are put into liquid nitrogen immediately, then they are freeze dried. The freeze-dried cubes are applied for EDS and XRD tests.

\section{B. Experimental Instruments}

1) EDS tests: In nature, the X-ray photon characteristic energy of different elements is different.

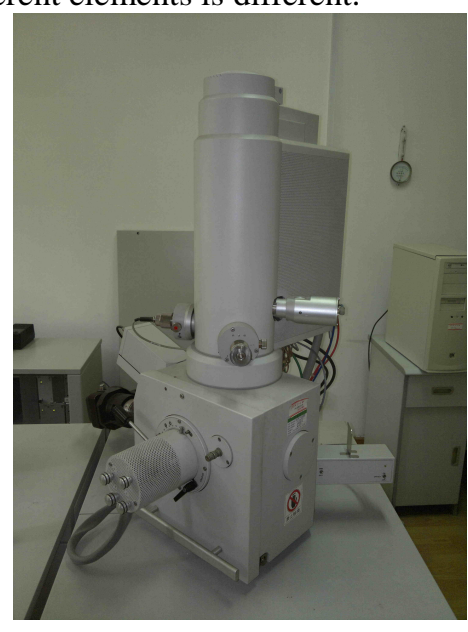

FIGURE I. 
The elemental composition of soils can be analyzed by this principle. The X-ray energy dispersive spectrometer used in this research is shown in Figure I. Its type is SIRION-100 and it is produced by FEI in Holland.

2) XRD tests: The XRD analysis is based on the principle that diffraction beam appears when X-ray passes through the crystal. The X-ray diffractometer used in this research is shown in Figure II. Its type is PANalytical X'Pert PRO and it is produced by PANalytical in Holland.

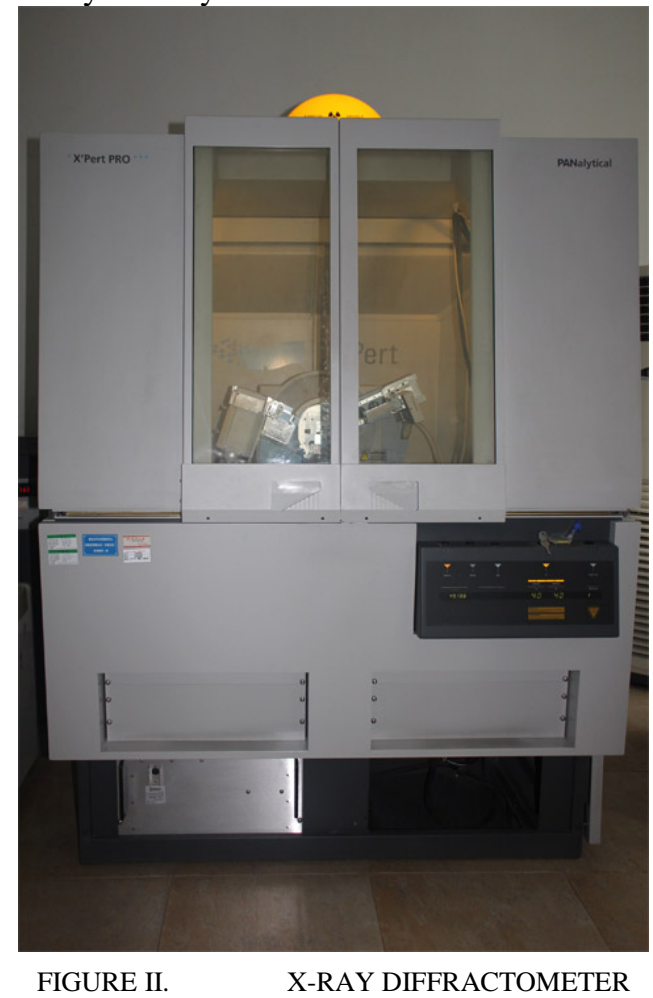

\section{EXPERIMENTAL RESULTS}

\section{A. EDS Results}

EDS tests were performed on Hangzhou soft clay and Hangzhou stiff clay respectively and the results were shown in Figure III[6]. In this figure, the irradiation energy with the unit of kilo electron volt $\left(\mathrm{keV}, 1 \mathrm{keV}=1.6022 \times 10^{-16} \mathrm{~J}\right)$ is used as abscissa and the disperse spectrum intensity without units is used as ordinate.

The mass percentages of main elements in Hangzhou soft clay and Hangzhou stiff clay are listed in Table II respectively [6]. It can be observed that the oxygen $(\mathrm{O})$, silicon( $\mathrm{Si})$, aluminum(Al) are the three important elements both in Hangzhou soft clay and Hangzhou stiff clay. It is worth mentioning that there is no sulfur(S) in Hangzhou stiff clay. However, S can be found in Hangzhou soft clay. As we all know, humus is a major component of organic matter in soils and $\mathrm{S}$ is one of main elements of humus. Hence, humus exists in Hangzhou soft clay because of the existence of S.

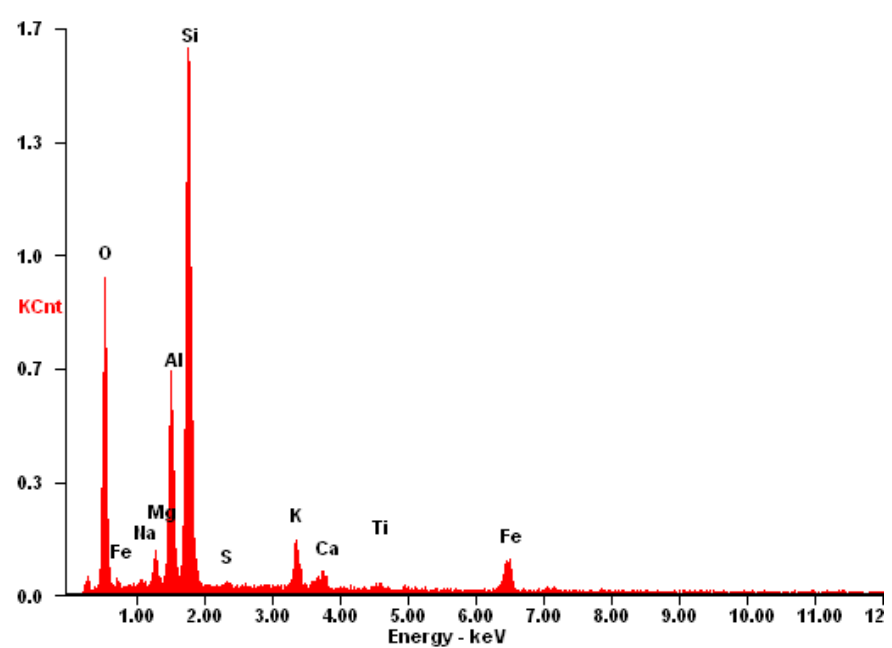

(A)

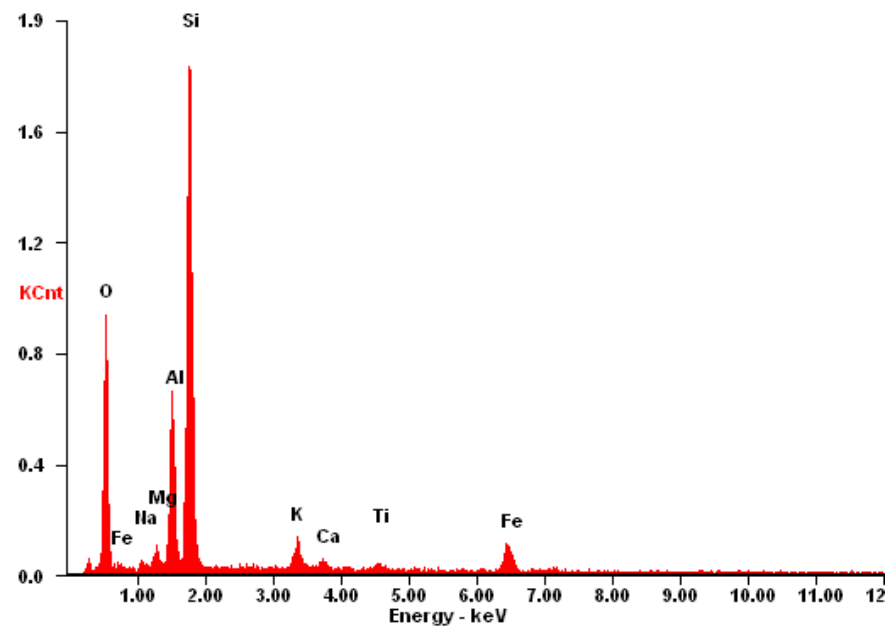

(B)

FIGURE III. $\quad$ EDS RESULTS: (A) HANGZHOU SOFT CLAY, (B) HANGZHOU STIFF CLAY

TABLE II. MASS PERCENTAGES OF MAIN ELEMENTS (\%)

\begin{tabular}{|l|c|c|c|c|c|c|c|c|c|c|}
\hline \multicolumn{1}{|c|}{ Sample } & $\mathbf{O}$ & $\mathbf{N a}$ & $\mathbf{M g}$ & $\mathbf{A l}$ & $\mathbf{S i}$ & $\mathbf{S}$ & $\mathbf{K}$ & $\mathbf{C a}$ & $\mathbf{T i}$ & $\mathbf{F e}$ \\
\hline $\begin{array}{l}\text { Hangzhou soft } \\
\text { lay }\end{array}$ & 46.65 & 0.73 & 1.83 & 11.47 & 29.85 & 0.39 & 2.80 & 1.03 & 0.59 & 4.68 \\
\hline $\begin{array}{l}\text { Hangzhou stiff } \\
\text { clay }\end{array}$ & 46.48 & 0.89 & 1.33 & 10.98 & 32.21 & -- & 2.20 & 0.68 & 0.75 & 4.48 \\
\hline
\end{tabular}

\section{B. XRD Results}

$\mathrm{XRD}$ tests were carried out to research the compounds in Hangzhou soft clay and Hangzhou stiff clay. The XRD result of Hangzhou soft clay is the top one in Figure IV(A) [6]. The spectrums beneath it stand for the most important crystal minerals in soils. The XRD result of Hangzhou stiff clay is shown in Figure IV (B). In Fig. 4.1, double diffraction angles with the unit of degree $\left({ }^{\circ}\right)$ is used as abscissa and the diffraction intensity without units is used as ordinate. It can be seen that main minerals are Quartz, Chlorite, Phlogopite, Anorthite both in Hangzhou soft clay and Hangzhou stiff clay. 


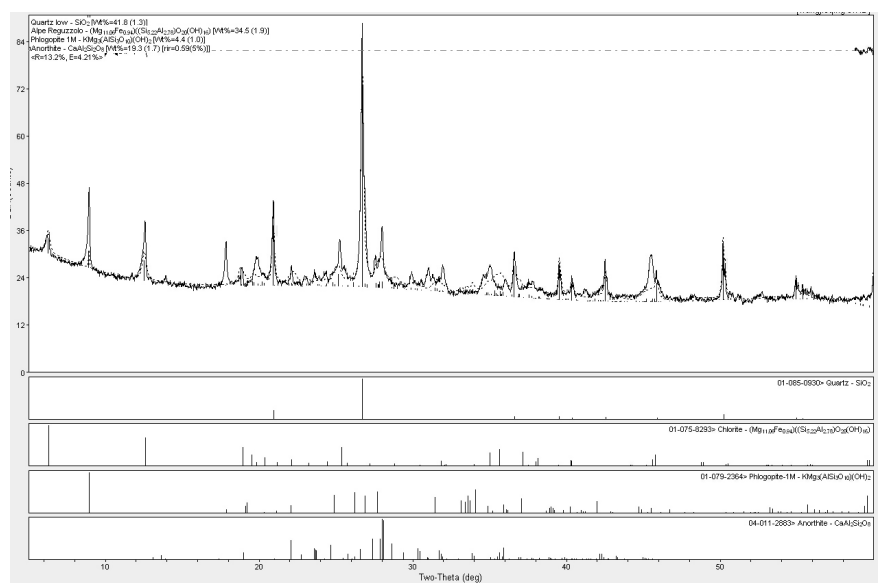

(A)

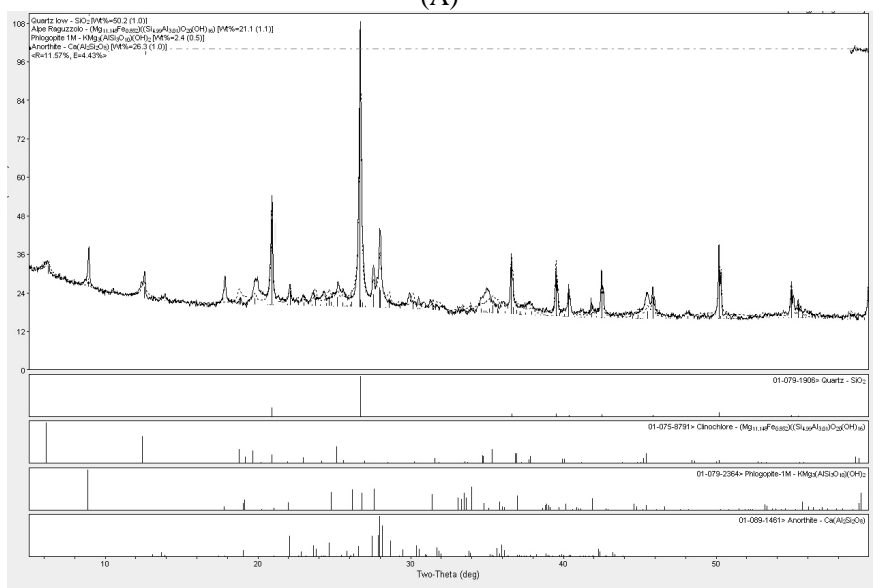

(B)

FIGURE IV.

XRD RESULTS: (A) HANGZHOU SOFT CLAY, (B) HANGZHOU STIFF CLAY

After the peaks in the XRD are positioned and measured, the relative content of different minerals can be roughly determined. According to the calculation results listed in Table III [6], the Quartz content and Anorthite content in Hangzhou soft clay are less than that in Hangzhou stiff clay. Nevertheless, the Chlorite content and Phlogopite content in Hangzhou soft clay are more than that in Hangzhou stiff clay. According to Mohs' scale of hardness, the hardness of Quartz, Anorthite, Chlorite, Phlogopite is 7, 6 6.5, 2 2.5, 2.5 respectively. Consequently, it can be roughly judged that the compressibility of Hangzhou soft clay is more considerable than that of Hangzhou stiff clay.

TABLE III. MASS PERCENTAGES OF MAIN MINERALS (\%)

\begin{tabular}{|c|c|c|c|c|}
\hline Sample & Quartz & Chlorite & Phlogopite & Anorthite \\
\hline Hangzhou soft clay & 41.8 & 34.5 & 4.4 & 19.3 \\
\hline Hangzhou stiff clay & 50.2 & 21.1 & 2.4 & 26.3 \\
\hline
\end{tabular}

\section{CONCLUSIONS}

In this paper, EDS and XRD tests are performed to investigate the chemical composition of Hangzhou soft clay and Hangzhou stiff clay. The following conclusions can be made:

- According to the EDS analysis, $\mathrm{S}$ can be found in Hangzhou soft clay but it can't be found in Hangzhou stiff clay. This implies that there is humus in Hangzhou soft clay because $\mathrm{S}$ is one of main elements of humus. Further chemical and biological analyses are yet to be performed on the samples to investigate the relationship between humus and tertiary consolidation behavior.

- Based on the XRD analysis, the Quartz content and Anorthite content in Hangzhou soft clay are less than that in Hangzhou stiff clay but the Chlorite content and Phlogopite content in Hangzhou soft clay are more than that in Hangzhou stiff clay. According to Mohs' scale of hardness, it can be roughly judged that the compressibility of Hangzhou soft clay is higher than that of Hangzhou stiff clay. The high compressibility of Hangzhou soft clay is explained in the sight of chemistry.

- Macro mechanical characteristics of soils can be explained according to the results of chemical analysis. More chemical and biological analyses should be carried out to study the mechanical behavior of soils.

\section{ACKNOWLEDGMENT}

Dr. Mingyong Yuan and Dr. Xiaoming Tang in the center of electron microscopy, Zhejiang University are acknowledged for their help in the EDS and XRD tests.

\section{REFERENCES}

[1] J. Zhou, and X. N. Gong, "Study on strain soften in saturated soft clay under cyclic loading,” China Civil Engineering Journal, vol. 33(5), pp. 75-78, 2000. (in Chinese)

[2] Y. Shen, J. Zhou, X. N. Gong, and H. L. Liu, “Intact soft clay's critical response to dynamic stress paths on different combinations of principal stress orientation,” Journal of Central South University of Technology, vol. 15(s2), pp. 147-154, 2008.

[3] J. Wang, Y. Q. Cai, and F. Yang, "Effects of initial shear stress on cyclic behavior of saturated soft clay,” Marine Georesources \& Geotechnology, vol. 31, pp. 86-106, 2013.

[4] J. Q. Huang, X. Y. Xie, J. Z. Li, and W. J. Wang, "Experimental Study of Micro Behavior of Hangzhou Soft Clay,” Electronic Journal of Geotechnical Engineering, vol. 19, pp. 6105-6120, 2014.

[5] Y. Ichikawa, K. Kawamura, N. Theramast, and K. Kitayama, "Secondary and tertial consolidation of bentonite clay: Consolidation test, molecular dynamics simulation, and multiscale homogenization analysis,” Mechanics of Materials, vol. 36, pp. 487-513, 2004.

[6] J. Q. Huang. "Theoretical and Experimental study on Nonlinear Finite Strain Consolidation,” Hangzhou: Zhejiang University, 2015, pp. 108112. (in Chinese) 